\title{
Generating Sales While Providing Service: A Study of Customer Service Representatives' Ambidextrous Behavior
}

Cross- and up-selling in inbound call centers is a growing business practice, with the promise of enhanced revenue generation and customer retention. Yet firms struggle to create conditions that are conducive to customer service representatives' (CSRs') concurrent engagement in service and sales. By developing a framework of the antecedents and performance consequences of aligned sales and customer service provision, this study advances understanding of ambidexterity at the employee level. The framework receives strong support from an empirical study based on CSRs' survey responses and matched performance data. A CSR's locomotion orientation facilitates ambidextrous behavior and interacts positively with an assessment orientation. However, team identification and bounded discretion impair this valuable interplay. Ambidextrous behavior also increases customer satisfaction and sales performance but decreases efficiency. Nevertheless, the overall performance effect is positive.

Keywords: ambidexterity, cross-/up-selling, customer service provision, employee level, regulatory modes

E conomic and competitive pressures have sparked firms' interest in adding a revenue component to their costly after-sales support. As a consequence, inbound call centers have introduced revenue generation as a strategic priority (CSO Insights 2007). Blending sales with service can reap increased revenues and customer retention rates. A McKinsey \& Co. report points out that inbound call centers have the potential to generate at least $10 \%$

Claudia Jasmand is a doctoral candidate, Department of Marketing and Supply Chain Management, School of Business and Economics, Maastricht University, The Netherlands, and an assistant professor, Organization and Management Group, Imperial College Business School, Imperial College London (e-mail: c.jasmand@imperial ac.uk). Vera Blazevic is an assistant professor, Institute for Management Research, Radboud University Nijmegen, The Netherlands, and a visiting professor, Technology and Innovation Management Group, RWTH Aachen University, Germany (e-mail: blazevic@tim .rwth-aachen.de). Ko de Ruyter is Professor of Marketing, Department of Marketing and Supply Chain Management, School of Business and Economics, Maastricht University, The Netherlands (e-mail: k.deruyter@maastrichtuniversity.nl). The authors thank Richard P. Bagozzi, Utpal Dholakia, Dhruv Grewal, Amir Grinstein, Venkatesh Shankar, Brian Sternthal, Alex da Mota Pedrosa, Nina Belei, Jan Pelser, Uwe Gross, and Philipp Wagner for their helpful comments on previous drafts of this article and Tobias Grossecker for project assistance. The authors gratefully acknowledge the constructive guidance of the three anonymous $J M$ reviewers. This article was accepted under Ajay K. Kohli's editorship. Gary Frazier served as coeditor. of a firm's total revenues from sales of new products and services (Eichfeld, Morse, and Scott 2006). Yet recent market studies reveal that the actual returns are far below such optimistic estimates (CSO Insights 2007; International Customer Management Institute 2007). Apparently, firms struggle to create conditions that are conducive to a successful alignment between customer service and sales.

Managerial literature is replete with illustrations of the challenges inbound call centers face (e.g., mycustomer.com, customerthink.com). Among the most commonly cited is customer service representatives' (CSRs') deeply ingrained view that additional selling is incommensurate with service, which creates a high mental barrier to blending the two tasks. Call centers also observe considerable heterogeneity in CSRs' ability to convert service calls into a crossor up-sale, which complicates the development of policies and guidelines designed to increase average performance (International Customer Management Institute 2007). Furthermore, the newly introduced revenue generation goals conflict with the efficiency goals that tend to rule traditional, service-only call centers (Aksin, Armony, and Mehrotra 2007). Firms clearly need an in-depth understanding of the factors that contribute to CSRs' ability to align their service and sales efforts, as well as the subsequent impact on key performance parameters.

Extant marketing literature rarely considers the simultaneous pursuit of service and sales goals however. Sales literature focuses on the performance effects of sales behaviors in relationship-oriented contexts (e.g., Plouffe, Hulland, and Wachner 2009), and services literature centers on the service provider's management of the customer experience (e.g., Price, Arnould, and Tierney 1995). The few 
studies that bridge these literature streams highlight the trade-offs involved in service-sales alignment but fail to explain how to resolve them (e.g., Evans, Arnold, and Grant 1999). Therefore, we turn to recent research on the phenomenon of ambidexterity, which reflects alignment in the pursuit of seemingly conflicting goals. Ambidextrous firms manage the conflicting demands of exploiting existing competencies and exploring new opportunities, and thus they enjoy superior performance (Raisch and Birkinshaw 2008). Recent theorizing demonstrates that ambidexterity ultimately becomes manifest at the employee level (Raisch et al. 2009). Ambidextrous employees perform contradictory activities in their pursuit of multiple goals, such as efficiency-oriented routine tasks and variability-increasing nonroutine tasks (Mom, Van den Bosch, and Volberda 2009). In a similar vein, CSRs increasingly are expected to fulfill service requests efficiently and reliably while also exploring cross-/up-selling opportunities. Despite the importance of the employees' ability to pursue seemingly conflicting goals, in-depth understanding of their ambidextrous behavior is lacking (Raisch et al. 2009). To address this theoretically and managerially relevant gap, we develop and empirically validate a framework of the antecedents and performance consequences of CSRs' ambidexterity in relation to the pursuit of service and sales goals.

This study advances ambidexterity theory in three ways. First, we conceptualize CSRs' ambidextrous behavior to clarify its specific nature and inherently conflicting demands. Such a clarification is necessary, given the ongoing debate about whether employees can be truly ambidextrous (Gupta, Smith, and Shalley 2006; Mom, Van den Bosch, and Volberda 2009) and the need to understand CSRs' ability to complete seemingly contradictory tasks. Second, we address the observable heterogeneity in individual CSRs' ambidextrous behavior by investigating the hitherto unstudied effects of individual motivations (Raisch et al. 2009). As engaging in ambidextrous behavior poses a self-regulatory and motivational challenge, we draw on regulatory mode theory (Kruglanski et al. 2000) and propose that the joint effect of CSRs' motivational orientations of locomotion and assessment enhances their ambidextrous behavior. We also investigate how prevalent structural call center contingencies, such as team identification (Ashforth and Mael 1989) and bounded discretion (Kelley 1993), may influence the valuable interplay of these two motivational orientations. Third, to the best of our knowledge, this study is the first to assess the performance implications of individual ambidexterity; we conceptualize and empirically test the validity of the ambidexterity-performance tenet at the personal level (Cao, Gedajlovic, and Zhang 2009). We investigate the specific impact of CSRs' ambidextrous behavior on their performance in terms of customer satisfaction, sales, and efficiency, which are of particular interest because of the commonly observed productivity-quality-revenue tradeoffs in frontline jobs (Marinova, Ye, and Singh 2008).

\section{Theoretical Background}

The notion of ambidexterity has attracted attention from diverse literature, including strategic management, organizational learning and design, and innovation. For this emerging topic, organizational ambidexterity refers to a firm's ability to pursue the seemingly conflicting goals of exploiting existing competencies and exploring new opportunities (Raisch and Birkinshaw 2008). The objective of exploitation, which includes activities such as refinement, implementation, and execution, is the creation of efficiency and reliability. Exploration instead pertains to activities such as search, discovery, and risk taking and centers on flexibility and creating variability (Levinthal and March 1993; March 1991). ${ }^{1}$ Because these two types of tasks are separate, nonsubstitutable, and interdependent, firms must find ways to achieve complementarity and carry out both (Gibson and Birkinshaw 2004; Levinthal and March 1993). Empirical studies provide support for the tenet that ambidexterity enhances a firm's performance (Raisch and Birkinshaw 2008). Yet the conflicting demands of the two types of activities (e.g., efficiency vs. flexibility) and their frequent competition for limited resources make it difficult to be ambidextrous (Gupta, Smith, and Shalley 2006; March 1991).

Traditionally, firms use structural mechanisms to overcome the tensions in their pursuit of seemingly conflicting goals. They might become ambidextrous by cycling through periods of these types of activities or developing different subunits that specialize in one or the other activity pattern (Gupta, Smith, and Shalley 2006). Recent empirical evidence suggests that contextual mechanisms, such as the creation of appropriate organizational contexts (e.g., concurrent discipline, stretch, support, trust) or coordination mechanisms (e.g., cross-functional interfaces), can work as well (Gibson and Birkinshaw 2004; Mom, Van den Bosch, and Volberda 2009). These efforts aim to encourage employees to pursue apparently conflicting goals and provide them with the behavioral capacities to think and behave ambidextrously. As Raisch et al. (2009) note, these advances suggest that a firm's ambidexterity is rooted in the employee's ability to manage disparate task demands and integrate them for cross-fertilization. Accordingly, employees' ambidextrous behavior shapes organizational performance; yet a conceptual and empirically validated understanding of employee-level ambidexterity is lacking (Raisch et al. 2009).

The requirements for employees to pursue seemingly conflicting goals simultaneously seems widespread, ranging from managers (Mom, Van den Bosch, and Volberda 2009), to researchers (Markides 2007), to production line workers (Adler, Goldoftas, and Levine 1999). Likewise, CSRs are now asked to provide customer service at constant quality and low cost and, at the same time, to engage in cross-/upselling to generate revenues during encounters initiated by customer service requests. Firms thus shift the responsibility for managing the dual emphasis on cost reduction and revenue expansion to CSRs, which complicates the existing

\footnotetext{
1"Exploitation" and "exploration" are prevalent umbrella terms in the organizational literature and refer to various conflicting demands at different organizational levels (e.g., efficiency and flexibility, search scope and search depth). We thank the anonymous reviewer team and the editor for pointing out that these terms have different and inappropriate connotations at the employee level. We therefore decided to use the terms "customer service provision" and "cross-/up-selling" for the underlying dimensions of ambidexterity in the context of CSRs' service-sales alignment.
} 
productivity-quality trade-off in the front line of the organization (Marinova, Ye, and Singh 2008; Rust, Moorman, and Dickson 2002).

Customer service provision pertains to CSRs' activities that aim to help customers fulfill their needs through their current product/service consumption portfolios. When providing customer service, CSRs respond to incoming customer service requests by implementing available, often prescribed, and standardized problem-solving procedures. The large call volumes and frequent recurrence of the same requests enable CSRs to rely on well-practiced processes and leverage routinely used knowledge and skills. The service conversations are typically structured and partly scripted to ensure constant quality and efficiency (Aksin, Armony, and Mehrotra 2007; Deery, Iverson, and Walsh 2002). Moreover, assessments of CSRs' customer service provision usually depend on their performance with regard to efficiency targets, such as call handling time, and reliability and quality targets, measured as customer satisfaction (Deery, Iverson, and Walsh 2002; Singh 2000).

In contrast, cross-/up-selling refers to CSRs' activities that aim to change (i.e., expanding or replacing parts of) customers' current product/service consumption portfolios, in accordance with their needs that cannot be satisfied by their current portfolios. Thus, during the service encounters, CSRs need to search proactively for customer needs and ways to satisfy them with a new product or service, discover suitable ways to turn the service into a sales conversation, and create and capture sales opportunities (Aksin and Harker 1999; Günes et al. 2010). They also need to leverage dispersed information to generate knowledge beyond what the service conversation usually offers and requires, because effective sales performance depends on an in-depth understanding of customer needs (Evans, Arnold, and Grant 1999; Weitz 1978). Furthermore, the customer's purchase willingness depends on many factors, such as previous satisfaction and financial resources (Günes et al. 2010). This information may not be readily available to CSRs, which turns cross-/up-selling into a process with uncertain returns and a high risk of failure. Because cross-/up-selling requires detecting the right product and time to attempt a sale (Günes et al. 2010), its success necessitates procedural flexibility.

Ambidextrous behavior refers to CSRs' engagement in both customer service provision and cross-/up-selling during service encounters. Because customers' service requests initiate the encounters, CSRs must simultaneously perform customer service and cross-/up-sell activities and/or quickly switch between them to display ambidextrous behavior. Such simultaneous pursuit of service and sales goals requires CSRs' to manage fundamentally different, if not conflicting, behavioral demands. On the one hand, customer service activities center on explicit service requests, readily available knowledge, and relatively standardized processes, emphasizing implementation and execution, akin to order taking. They involve the repetitious routine and structure necessary to achieve the goals of reliability and efficiency. On the other hand, cross-/up-selling activities imply proactive, broad, and nonroutine searches for customer needs, knowledge generation, and creation of opportunities, akin to order seeking. They involve risk taking, flexibility, and uncertain returns because the identification, positioning, and closing of a sale largely depend on the nature of service requests and customers and how the conversation develops. The uncertainty and variability involved in cross-/up-selling are detrimental to the reliability and efficiency focus of customer service provision; the latter may crowd out risk-taking and proactive cross-/up-selling efforts. Furthermore, pursuing service and sales goals often requires CSRs to trade off the allocation of their time, effort, and attention to both types of activities (Aksin and Harker 1999; Evans, Arnold, and Grant 1999).

Several researchers have questioned the compatibility of the constituent dimensions of ambidexterity at the employee level (Gupta, Smith, and Shalley 2006; March 1991), though others have observed that employees can simultaneously and sequentially attend to them (Adler, Goldoftas, and Levine 1999; Mom, Van den Bosch, and Volberda 2009). For CSRs, we predict compatibility. Prior literature indicates that service and sales activities are compatible because they share common ground. A common set of abilities, such as diagnostic behavior, empathy, and interpersonal adaptation, underlies both of them (e.g., Evans, Arnold, and Grant 1999; Gwinner et al. 2005; Saxe and Weitz 1982). Previous research further suggests that people can simultaneously perform routine tasks using automatic processes and rely on controlled processes for their nonroutine tasks (Wegner and Bargh 1998). Thus, some customer service activities might be performed in automatic mode to free up cognitive and attentional resources for cross-/up-selling. Consequently, we posit that it is possible for CSRs to engage, simultaneously and/or sequentially, in customer service provision and cross-/up-selling during a service encounter.

Although service and sales goals are not completely incompatible in their requirements for underlying abilities, they seem conflicting in their behavioral demands and often compete for CSRs' resources. As such, engaging in ambidextrous behavior requires CSRs to manage seemingly conflicting task demands, which poses a substantial selfregulatory and motivational challenge in the process of pursuing multiple goals.

Research into self-regulation has examined how people direct attention, resources, and action in goal pursuit by dealing with change (i.e., making progress toward the goal) and comparison (i.e., monitoring the progress) (e.g., Carver and Scheier 2010). In this literature, the two regulatory mode orientations of locomotion and assessment have emerged to reflect the motivational capacity of people to guide themselves effectively toward important goals (Higgins, Kruglanski, and Pierro 2003). Regulatory mode theory views self-regulation as consisting of two independent dimensions. Locomotion denotes movement away from a current state, which is independent of the value of the current state and its relationship to goals, while assessment refers to evaluations of current states, goals, and means and comparisons among them (Kruglanski et al. 2000). Empirical studies show that people reliably differ in their preferences for locomotion and assessment, which influences the manner in which they approach tasks, pursue goals, make decisions, evaluate themselves and others, and deal with challenges (Kruglanski et al. 2010). These studies also demonstrate that a desire for movement and progress is unrelated to the preference for critical evaluation and comparison, such that a person can be high on both 


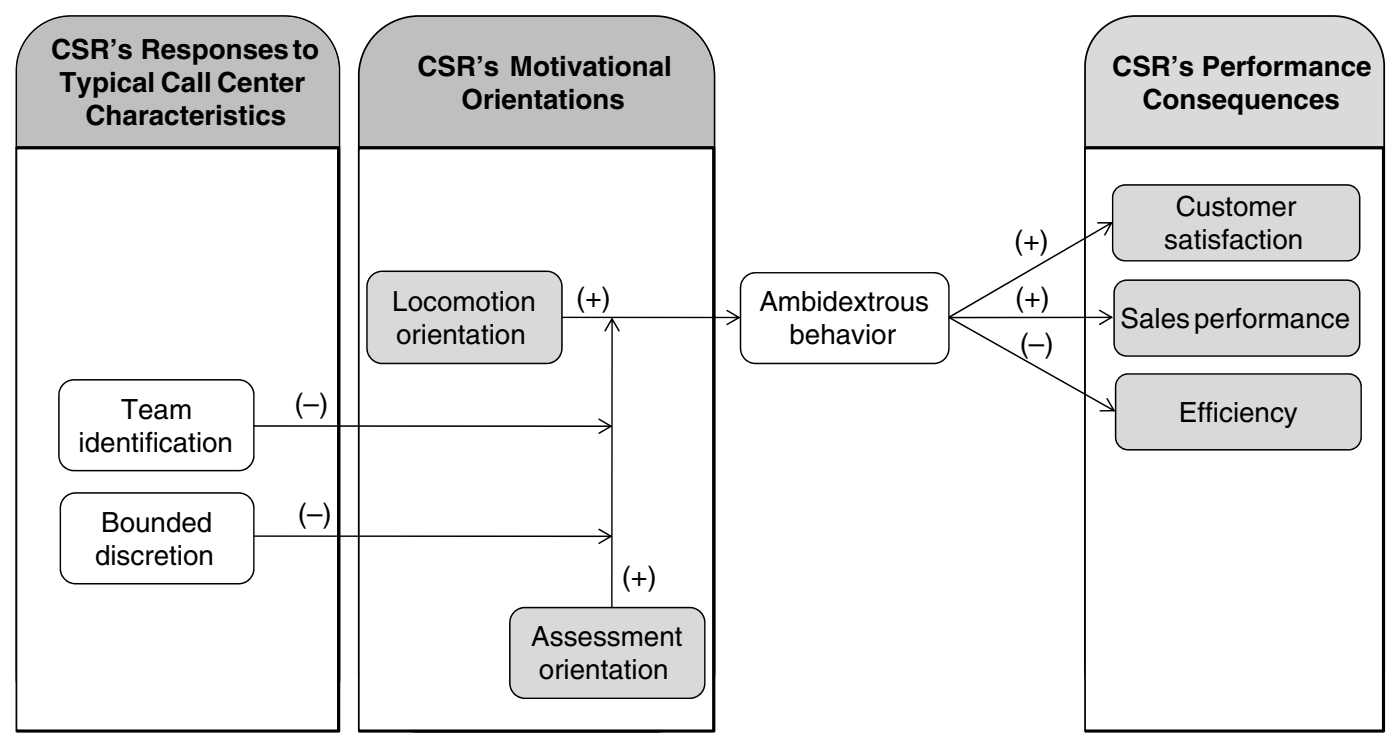

locomotion and assessment or high or low on one or the other. Previous research into these motivational orientations indicates that in combination, they lead to superior selfregulation in challenging and difficult endeavors, such as demand for ambidextrous behavior (Kruglanski et al. 2000; Pierro, Kruglanski, and Higgins 2006). We therefore study the effects of CSRs' locomotion and assessment orientations in regulating their behavior toward seemingly conflicting goals. By investigating such individual differences, our study complements existing research that focuses on the effects of supporting contextual factors on ambidexterity (Gibson and Birkinshaw 2004; Mom, Van den Bosch, and Volberda 2009).

We also consider CSRs' responses to prevalent structural call center characteristics because self-regulation and motivation in goal pursuit are intertwined with social, situational, and environmental conditions (e.g., Fitzsimons and Bargh 2004). Inbound call centers typically organize CSRs around team structures to encourage the creation of a collective team identity that motivates performance, cooperation, and mutual support (Ashforth, Harrison, and Corley 2008; Deery, Iverson, and Walsh 2002). Moreover, call center operations focus on standardization, routines, and efficiency. Therefore, work is generally formalized with standards and rules that provide guides for workflows, tasks, and procedures to encourage CSRs to exercise bounded discretion (Aksin, Armony, and Mehrotra 2007; Kelley 1993). Because team identification and bounded discretion may create conditions that interfere with the functionality of the motivational orientations, we consider these interactions.

Finally, we investigate the performance implications of CSRs' ambidextrous behavior. To the best of our knowledge, this study is the first to assess the validity of the ambidexterity-performance tenet at the employee level. The tenet rests on the assumption that customer service provision and cross-/up-selling are complementary (Cao,
Gedajlovic, and Zhang 2009). Complementarity may be reflected differently in various performance parameters (for a similar view, see Raisch and Birkinshaw 2008), particularly given the observed trade-offs among performance outcomes of business units with frontline service jobs (Marinova, Ye, and Singh 2008). Therefore, we consider the effects of ambidextrous behavior on the CSR's performance in terms of customer satisfaction, sales, and efficiency, which are critical performance parameters in inbound call centers that aim to align service and sales. We provide our conceptual framework in Figure 1.

\section{Hypotheses Development}

\section{Effects of Locomotion and Assessment Orientations on Ambidextrous Behavior}

Locomotion orientation. A locomotion orientation constitutes a preference for movement away from a current state (in either an experiential or a psychological sense) when pursuing goals. This preoccupation with moving forward reflects the desire to choose any activity to work on rather than standing still and waiting to commence the activity (Higgins, Kruglanski, and Pierro 2003; Kruglanski et al. 2000). Locomotion-oriented people prefer to get started on a task and expend effort to move quickly on to the next one, and they enjoy being in motion, rather than critically evaluating to determine whether the course of action is in the right direction. In other words, their focus is on "getting on with it" to make things happen (Kruglanski et al. 2010). They are intrinsically motivated to engage in activities and tend to perceive such actions as ends in themselves rather than means (Higgins, Kruglanski, and Pierro 2003). For them, the greater the sense of movement, the more they feel intrinsically rewarded (Avnet and Higgins 2003). The popular Nike slogan "Just do it" is an apt reflection of this orientation (Kruglanski et al. 2000). 
Ambidextrous behavior is inevitably linked with the motivation to deal, simultaneously and/or sequentially, with disparate task demands in the pursuit of multiple service and sales goals. High-locomotion-oriented CSRs, with their desire for action and change, may be more motivated to do so. Previous research indicates that high-locomotionoriented people welcome changing conditions and new experiences, react positively to changes in their task environment, and prefer a broad variety of tasks, possibly because doing different rather than similar things gives them a greater sense of progress and movement (Avnet and Higgins 2003; Kruglanski et al. 2007; Pierro, Kruglanski, and Higgins 2006). Thus, high-locomotion-oriented CSRs should be more likely to seek switching between (or simultaneously engaging in) fundamentally different activities, such as closely listening to a customer's service request and searching for a sales opportunity, than repeatedly doing the same type of activity.

In addition, locomotion-oriented people pay less attention to the potential consequences of their decisions and actions, because they prefer to get started quickly on tasks and make swift decisions to "make something happen" and keep moving forward (Higgins, Kruglanski, and Pierro 2003; Pierro et al. 2008). Thinking less about the implications of activity engagement should decrease awareness of potentially conflicting outcomes and weaken perceptions of incompatibility of activities and goals. Therefore, high-locomotion-oriented CSRs may be less sensitive and receptive to trade-offs and conflicting demands, which is conducive to engaging in ambidextrous behavior. Finally, previous research suggests that people attend more to motivationally salient cues and tend to see what they desire to see (Balcetis and Dunning 2006; Lang, Bradley, and Cuthbert 1997). For locomotionoriented people, every cue that signals an opportunity to do something is motivationally salient. Because of their urge to make use of such opportunities in relative disregard of personal benefits and costs (Higgins, Kruglanski, and Pierro 2003), locomotion-oriented CSRs should be more likely to engage simultaneously and sequentially in customer service and cross-/up-sell activities regardless of situational obstacles, difficulties, or constraints. We thus expect highlocomotion-oriented CSRs to be more likely to engage in ambidextrous behavior.

$\mathrm{H}_{1}$ : A CSR's locomotion orientation is positively related to his or her ambidextrous behavior.

Assessment orientation. An assessment orientation refers to a preference for critical comparison of alternative states, means, and goals to judge their relative worth (Kruglanski et al. 2000). It reflects a desire for careful analysis to be accurate and make the ideal choice (Higgins, Kruglanski, and Pierro 2003). In contrast with locomotors, assessmentoriented people prefer to wait and evaluate all possible choices thoroughly before deciding how to act. In other words, they have a tendency to keep thinking without leaping. In decision making, for example, assessors favor a strategy that allows them to make as many comparisons as possible without reducing the set of alternatives to arrive at the best decision (Avnet and Higgins 2003). An assessment orientation is reflected in the popular phrase "do the right thing" (Kruglanski et al. 2000).
Previous research indicates that assessment-oriented people have strong self-evaluative concerns; they continuously compare themselves with external standards, such as goals, norms, and other people, and worry about how their performance will be perceived by others (Higgins, Kruglanski, and Pierro 2003). An assessment orientation signifies great sensitivity to feedback and discrepancies of any kind. Empirical studies show that high-assessment-oriented people are better at detecting errors and deficiencies, while also coming up with more alternative means to eliminate such imperfections (Kruglanski et al. 2000). Given this enhanced sensitivity to standards, feedback, and discrepancies, high(vs. low-) assessment-oriented CSRs should be more aware of their multiple service and sales goals and inclined to assess continuously how their performance measures up to these standards. With their desire for critical comparison and evaluation of alternatives, they should be preoccupied with determining the right means, courses of action, and time needed to achieve each of these goals, because doing so would reflect positively on them. We expect this enhanced sensitivity to performance gaps in service and sales goals and concern with ideal choice to purposefully guide high-locomotion-oriented CSRs' resource investments into customer service and cross-/up-selling activities in the direction of the multiple job goals. Such assessmentoriented guidance should result in high-locomotion-oriented CSRs achieving superior levels of ambidextrous behavior.

We do not expect an assessment orientation to affect ambidextrous behavior directly however. Previous studies indicate that high-assessment-oriented people primarily form behavioral intentions that lead to successful goal attainment only if they also have high locomotion concerns (Higgins, Kruglanski, and Pierro 2003). Research demonstrates that the combined effect of locomotion and assessment orientations results in successful self-regulation in challenging and difficult endeavors (Kruglanski et al. 2010). Effective self-regulation in the pursuit of seemingly conflicting service and sales goals requires CSRs to be eager to initiate continuously and keep on performing customer service and cross-/up-selling activities, while also wisely managing their effort and resources.

$\mathrm{H}_{2}$ : There is a positive interaction effect of locomotion and assessment orientations on ambidextrous behavior, such that the higher a CSR's assessment orientation, the stronger is the relationship between a CSR's locomotion orientation and ambidextrous behavior.

\section{Moderating Effects of CSRs' Responses to Typical Call Center Characteristics}

Team identification. Team identification refers to a CSR's perception of oneness with or belongingness to the team (Ashforth and Mael 1989). The CSRs who strongly identify with their team perceive the team's goals, norms, and values as their own (Dutton, Dukerich, and Harquail 1994; Van Knippenberg 2000). This sense of oneness with the team guides CSRs to behave in team-typical ways to endorse their team congruent identity (Haslam, Powell, and Turner 2000). When the team congruent identity is salient, CSRs use the team's goals, norms, and values in regulating their behavior, with the aim to conform to a shared team consensus, enhance well-being, and thereby feel a high belongingness to the team (Ashforth, Harrison, and Corley 
2008). Such conformity to consensus reduces the range of means that can potentially be employed in goal attainment. The CSRs then engage in team convergent thinking and reduce active consideration of other possible alternatives in their pursuit of goals. While team identification limits the continuous questioning of alternative options, assessment orientation needs active deliberation and critical reflection to purposefully guide locomotion behavior, which results in greater variability in judgment (Kruglanski et al. 2010). High levels of team identification therefore disrupt the continuous, considerate deliberation of alternatives, which is central to the assessment orientation. We thus expect that strong team identification reduces the effectiveness of an assessment orientation in guiding high-locomotion-oriented CSRs' engagement toward ambidextrous behavior.

$\mathrm{H}_{3}$ : A CSR's team identification weakens the positive interaction effect of the locomotion and assessment orientations on ambidextrous behavior, such that the positive relationship between locomotion orientation and ambidextrous behavior is strongest when a CSR's assessment orientation is high and team identification is weak.

Exercise of bounded discretion. Employees exercising bounded discretion perform their job tasks by relying on (self-)developed routines that are largely based on organizationally prescribed standards, processes, and rules (Kelley, Longfellow, and Malehorn 1996). Employees use bounded discretion when they choose a possible action from a prescribed list. For example, in call center settings, organizational trainings, manuals, and other colleagues provide employees with routine procedures for many tasks. This differentiates bounded discretion from stronger types of discretionary behavior, such as creative or deviant discretion, in which employees develop alternative means that are not formally specified or even engage in counterrole behavior (Kelley 1993). Exercising bounded discretion refers to the rather strict enactment of routines and implies a structured, well-practiced approach to the work tasks (Kelley 1993). In a self-regulation context, bounded discretion means the deployment of a restricted and predefined number of means in goal pursuit (March and Simon 1958). Because of the limited choice of alternative actions (in contrast with "free format" work practice), bounded discretion involves only a minimal level of active deliberation (Kelley, Longfellow, and Malehorn 1996). The CSRs exercising high bounded discretion want to ascertain the flow of activity, while reducing cognitive effort. This is a common phenomenon in a highly standardized service environment. Yet, when CSRs strictly follow routines, their assessment orientation is disrupted and inhibited. Prior research has shown that high-assessment-oriented people enjoy a maximum amount of options in goal pursuit and prefer critical comparative evaluations (Avnet and Higgins 2003). They want their task flow to be disrupted by continually considering what their options are, instead of relying on actions based on predescribed routines. If these people now strictly follow the routines and, thus, only have a limited set of options, they are less likely to use their assessment orientation, and critical evaluations to find the optimal course of action are inhibited. We thus expect that high levels of bounded discretion reduce the effectiveness of the assessment orientation for purposefully guiding high-locomotion-oriented CSRs' engagement in ambidextrous behavior.
$\mathrm{H}_{4}$ : The exercise of bounded discretion weakens the positive interaction effect of the locomotion and assessment orientations on ambidextrous behavior, such that the positive relationship between locomotion orientation and ambidextrous behavior is strongest when a CSR's assessment orientation is high and exercise of bounded discretion is low.

\section{Performance Consequences of CSRs' Ambidextrous Behavior}

For the ambidexterity-performance tenet to hold at the employee level, customer service provision and cross-/upselling should be complementary in their effects on performance. To provide a first, fine-grained validity test of the ambidexterity-performance tenet for CSRs, we focus on customer satisfaction, sales performance, and efficiency. Customer satisfaction refers to customers' level of contentment with the service encounters supplied by the CSR. Sales performance pertains to the proportion of a CSR's service encounters during which the CSR successfully extends a customer's product portfolio in terms of its size and/or value. Efficiency refers to the average total time a CSR spends per customer, such that efficiency decreases with increasing expenditure of time per customer.

Customer satisfaction. We expect cross-/up-selling to enhance the effectiveness of customer service provision with regard to customer satisfaction for several reasons. First, cross-/up-selling leads to increased knowledge about products and their benefits, which enables CSRs to address service requests better or faster. Enhanced product knowledge helps CSRs determine when a new product is a better solution to the customer's problem or when it augments solution quality. Knowledge about the product benefits customers seek can enhance CSRs' understanding of the severity of certain problems for customers, such that they can select more appropriate means to address these problems and better adapt to customers' emotional states, which implies greater service quality and customer satisfaction (Brady and Cronin 2001; Hennig-Thurau et al. 2006). Second, the large call volumes and repetitive nature of customer service provision may cause CSRs to fall into an assembly line mode of dealing with customers (Evans, Arnold, and Grant 1999). Customers perceive lower service quality when treated this way (Brady and Cronin 2001). However, cross-/up-selling attempts require CSRs to deal more intensively with customers, listen more closely, and acquire a deeper understanding of their needs and experience (Evans, Arnold, and Grant 1999). In turn, customers might perceive the CSR as more attentive, responsive, and authentic, enhancing their quality perceptions and satisfaction (Smith, Bolton, and Wagner 1999). We expect cross-/ up-selling to contribute to the effectiveness of customer service provision in shaping customer satisfaction.

$\mathrm{H}_{5}$ : A CSR's ambidextrous behavior is positively related to customer satisfaction.

Sales performance. Customer service provision should contribute to the effectiveness of cross-/up-selling with regard to sales performance. First, customer service provision involves communication with customers and access to customer information (e.g., database records), which may reveal potentially sales-relevant information and enhance 
understanding of the customers' needs and experience (Evans, Arnold, and Grant 1999). Such insight is important for effective selling (Weitz, Sujan, and Sujan 1986). Customer service provision also could create an elaborate knowledge structure of customer types and product consumption portfolios. This knowledge would facilitate the categorization of customers and situations and the identification of potential sales opportunities, enhancing sales effectiveness (Weitz, Sujan, and Sujan 1986). Second, the adequate handling of service requests may produce favorable customer perceptions of the CSR's credibility, competence, and capability to address their needs. Such perceived characteristics can serve as bases of influence that underlie commonly employed influence tactics in sales situations (Weitz 1981). Moreover, proper responses to customer service requests can induce positive customer reactions (Bitner, Booms, and Tetreault 1990), such as reciprocal behaviors that feature increased sharing of information and listening to the CSR, creating a fertile ground for sales efforts to flourish. We therefore expect customer service provision to contribute to the effectiveness of cross-/upselling efforts.

$\mathrm{H}_{6}$ : A CSR's ambidextrous behavior is positively related to sales performance.

Efficiency. In contrast, we expect efficiency losses to result from ambidextrous behavior for CSRs, which is detrimental to inbound call centers' priority parameters (Aksin, Armony, and Mehrotra 2007). Prior literature indicates that cross-/up-selling activities, in addition to customer service provision, lengthen customer-CSR interactions and reduce efficiency at the CSR level (e.g., Aksin and Harker 1999). Moreover, Marinova, Ye, and Singh (2008) find that employees in service occupations prioritize quality over efficiency. Accordingly, we expect that ambidextrous behavior leads to efficiency losses for CSRs.

$\mathrm{H}_{7}$ : A CSR's ambidextrous behavior is negatively related to efficiency.

\section{Methodology Research Setting and Data Collection}

We conducted an empirical study in cooperation with a national branch of a global call center provider (i.e., the company provides call center outsourcing services to client companies). We collected data through an online survey of CSRs at two call center sites. These CSRs work for several business lines of a client company that provides telecommunication services. As such, there are differences in the product/service portfolios these CSRs represent and the customer mix they serve. The CSRs handle typical inbound customer service tasks, such as answering incoming questions and responding to complaints. Technology-supported, standardized instructions define the process for handling most types of customer service requests and problems. As part of their daily jobs, these CSRs also should make cross-/ up-sale offers to customers. For many calls, they receive product suggestions from the system, but they have latitude in their choice of product and when and how to offer it (i.e., the sales process is not scripted and largely unspecified). As is common in the call center industry, the representatives, who perform their tasks individually, are organized in teams of 8 to $15 \mathrm{CSRs}$, each led by a team manager. Individual team members and team managers often initiate team-building activities. Management sets customer satisfaction, sales performance, and efficiency goals for the CSRs and the teams. The set goals result from the call center provider's negotiations with the different business lines of the client company, considering industry standards and benchmarks. Team managers regularly monitor CSRcustomer interactions and evaluate the CSRs' performance in one-on-one meetings and team performance in group meetings. The latter also serve as a platform to share learning experiences and exchange best practices among team members.

For the survey and performance data collection, we obtained approval from the national headquarters and call center site managers. During this approval process, we received helpful suggestions about our questionnaire and data collection. The author team sent e-mail invitations with the link to the online survey in two waves, to which 202 CSRs were randomly assigned. We guaranteed complete anonymity and confidentiality. Both waves lasted two and a half weeks and took place consecutively. In each wave, a reminder e-mail followed one and a half weeks later. To express our gratitude for the CSRs' participation in the survey, we raffled ten individual shopping vouchers and one team voucher, which a CSR could win for his or her team, among the respondents. One month after the survey study, we obtained performance data from the two call center sites. The performance data included weekly average call handling time, conversion rate, and customer satisfaction (through customer surveys) for the CSRs who were invited to participate in the study. They covered a period of seven weeks, spanning a window of about one week before and one week after the survey study. We matched the performance and survey data using code numbers, which guaranteed anonymity.

We obtained answers from 119 CSRs, for a response rate of $58.9 \%$. The sample consists of 68 female CSRs $(57.1 \%)$. The age distribution in the sample (in years) is as follows: $18-25(32.8 \%), 26-35(33.6 \%), 36-45(19.3 \%)$, and $>46$ $(14.3 \%)$. The CSRs have worked, on average, 2.52 years $(\mathrm{SD}=2.53)$ in the call center industry, .90 years $(\mathrm{SD}=1.38)$ in the current team, and 1.61 years $(\mathrm{SD}=1.51)$ as CSRs with cross-/up-selling responsibilities. A comparison of the profile of the CSR sample with profiles reported in other studies (e.g., Gwinner et al. 2005; Singh 2000) and the general CSR population at the call center provider suggests the representativeness of our sample. The respondents are almost equally distributed between the two call center sites (45.4\% and 54.6\%) and come from 25 teams. On average, we had 4.76 respondents per team.

\section{Measures}

Independent variables. Because measures for customer service provision and cross-/up-selling were not available in existing literature, we developed new scales in a separate, extensive, multistage study, following established procedures (Netemeyer, Bearden, and Sharma 2003). We developed initial item pools based on (1) an extensive review of 
sales and services literature; (2) interviews with ten CSRs, five team managers, and three customer experience managers working at one call center site involved in the current study, as well as in two other sites; and (3) intensive on-site fieldwork, including listening in on service and sales calls. The items underwent sorting and judgment tasks, aided by six academic experts and two practitioners, to achieve trimmed and refined item pools. We subjected the remaining items to a quantitative study among the CSRs with cross-/up-selling responsibilities at three call center sites to assess the psychometric properties. The analysis provided evidence of convergent and discriminant validity of the two constructs. $^{2}$

For the other study constructs, we relied on existing scales. The Appendix provides an overview of the items and corresponding references. To control for possible effects on our dependent variables, we also measured the CSR's job satisfaction ("All in all, I am satisfied with my job"), work experience as a CSR with cross-/up-selling responsibilities (e.g., 2.5 years), and general demographics.

Dependent variables. A third-party provider that randomly surveys customers after their interaction with a CSR collected the customer satisfaction data. Customers rated their satisfaction with the encounter supplied by the CSR on a five-point Likert scale ranging from "extremely dissatisfied" to "extremely satisfied." We received weekly averages of customer satisfaction per CSR. For sales performance and efficiency, we received conversion rate and call handling time data from the call center sites. The conversion rate reflects the number of calls during which the CSR sold

\footnotetext{
${ }^{2}$ The confirmatory factor analysis with the 12 items for customer service provision and cross-/up-selling (see the Appendix) provided indexes that indicate adequate model fit $\left(\chi^{2}(53)=68.074\right.$, comparative fit index $=.977$, Tucker-Lewis index $=.972$, root mean square error of approximation $=.046$, and standardized root mean square residual $=.046)$. Factor loadings ranged from .663 to .828 and were significant $(p<.01)$. All items loaded on their designated factor with no significant cross-loadings. Construct reliabilities for customer service provision (.90) and cross-/ up-selling (.88) were above the recommended threshold (Bagozzi and Yi 1988). Average variances extracted (AVE) for customer service provision (.61) and cross-/up-selling (.55) were greater than the .50 criterion (Fornell and Larcker 1981). Their square roots exceeded the correlation between the two constructs $(r=.058$, $p>.05)$ and thus passed Fornell and Larcker's (1981) test, indicating discriminant validity. We also assessed the extent to which the two constructs are distinct from other types of sales and service behavior: customer-oriented selling $(\mathrm{AVE}=.61)$ and selling orientation $(\mathrm{AVE}=.62)$ (Periatt, LeMay, and Chakrabarty 2004; Saxe and Weitz 1982) and interpersonal adaptive behavior $(\mathrm{AVE}=.56)$ and service-offering adaptive behavior $(\mathrm{AVE}=.55)$ (Gwinner et al. 2005). The square roots of all AVEs exceeded the interconstruct correlations (cross-/up-selling with customeroriented selling: $\mathrm{r}=.215, p<.05$, and with selling orientation: $\mathrm{r}=.047, p>.05$; customer service provision with interpersonal adaptive behavior: $\mathrm{r}=-.110, p>.05$, and with service-offering adaptive behavior: $\mathrm{r}=.227, p<.05)$. As expected, these results show that customer service provision and cross-/up-selling are empirically distinct from other types of service and sales behavior.
}

a product relative to the total number of calls handled by the CSR (per week), expressed as a percentage. It does not consider value or type of products sold. Call handling time is the average number of minutes a CSR spent per customer (call length plus postprocessing time) per week. For all three data types, we averaged the weekly scores per CSR. To account for variations in performance due to call center site and business line characteristics (e.g., nature of products and services, customer mix, and markets), we adjusted these average scores by the goals set for the CSRs, as follows: [(achieved score - goal)/goal]. For efficiency, we reversed the sign of this ratio. The final performance measures represent positively increasing scales for customer satisfaction, sales performance, and efficiency.

Checks. To rule out the possibility of systematic effects on our data and hypothesis testing, we took several measures. We probed for selection and nonresponse bias by comparing (1) early and late respondents on our key study variables and respondent profiles, (2) the performance levels of respondents and nonrespondents according to the matched performance data, (3) first- and second-wave respondents, and (4) respondents from the two call center sites. None of these comparisons revealed any differences.

To minimize common method variance, we followed Podsakoff, MacKenzie, and Podsakoff's (2003) suggestions: We obtained measures for the dependent variables and other variables from different sources. We psychologically separated the measures of the independent variables from those of customer service provision and cross-/up-selling by placing them into different thematic sections in the questionnaire, such that they appeared unrelated. Finally, we protected the CSRs' anonymity, clarified that the study's purpose was not to evaluate them in any way, and emphasized our interest in their personal perceptions, opinions, and behavior. Accordingly, we aimed to reduce evaluation apprehension and demands for social desirability.

\section{Measurement Model and Analysis Approach}

The relatively small sample size $(\mathrm{n}=119)$ and large number of items $(>40)$ produced a highly unfavorable item-tocases ratio. We therefore relied on the partial disaggregation approach (Bagozzi and Heatherton 1994) to minimize any loss of information in the latent factors, increase the accuracy of the parameter estimates (compared with total aggregation), and improve the ratio of sample size to parameter estimates (Coffman and MacCallum 2005). An assumption underlying all methods used to form parcels is unidimensionality. Our exploratory factor analyses with the original number of items for each construct provided evidence that the items loaded on the appropriate factors. We then formed parcels with a random item-to-parcel assignment (Bagozzi and Edwards 1998). The Appendix lists the items that form the respective parcels for each construct. We did not parcel the items for customer service provision and cross-/ up-selling, which are new scales. To prevent our parceling strategy from affecting our model estimations, we repeated all the analyses with new item-to-parcel combinations. The analyses did not reveal any differences in fit for the measurement model or in the pattern of significant structural parameter estimates. 
TABLE 1

Descriptive Statistics and Intercorrelations

\begin{tabular}{lccccccccccccc}
\hline & $\mathbf{1}$ & $\mathbf{2}$ & $\mathbf{3}$ & $\mathbf{4}$ & $\mathbf{5}$ & $\mathbf{6}$ & $\mathbf{7}$ & $\mathbf{8}$ & $\mathbf{9}$ & $\mathbf{1 0}$ & $\mathbf{1 1}$ & $\mathbf{1 2}$ & $\mathbf{1 3}$ \\
\hline 1. Customer satisfaction & 1.00 & & & & & & & & & & & \\
2. Sales performance & .04 & 1.00 & & & & & & & & & & \\
3. Efficiency & -.10 & -.17 & 1.00 & & & & & & & & & \\
4. Customer service provision & $.44^{* *}$ & .11 & -.20 & 1.00 & & & & & & & & \\
5. Cross-/up-selling & .10 & $.22^{*}$ & -.07 & -.02 & 1.00 & & & & & & & \\
6. Ambidextrous behavior & $.37^{* *}$ & $.26^{* *}$ & $-.18^{*}$ & $.61^{* *}$ & $.78^{* *}$ & 1.00 & & & & & & \\
7. Locomotion orientation & .06 & .08 & -.03 & .01 & $.35^{* *}$ & $.28^{* *}$ & 1.00 & & & & & \\
8. Assessment orientation & -.06 & .08 & .07 & -.02 & .06 & .04 & .04 & 1.00 & & & & \\
9. Team identification & .01 & .05 & -.17 & -.01 & $.24^{* *}$ & $.18^{*}$ & $.31^{* *}$ & .08 & 1.00 & & & \\
10. Bounded discretion & -.03 & .02 & -.08 & .03 & -.03 & .00 & .03 & $.34^{* *}$ & $.32^{* *}$ & 1.00 & & \\
11. Age & -.04 & .11 & $-.29^{* *}$ & -.06 & $.18^{*}$ & .10 & .09 & -.08 & .07 & .04 & 1.00 & \\
12. Work experience & $.21^{*}$ & $.20^{*}$ & .01 & .04 & .03 & .05 & -.01 & -.03 & -.07 & $-.26^{* *}$ & .11 & 1.00 \\
13. Job satisfaction & .08 & .04 & -.03 & .03 & $.28^{* *}$ & $.23^{* *}$ & $.33^{* *}-.12$ & $.32^{* *}-.07$ & .06 & -.05 & 1.00 \\
M & -.07 & .27 & .01 & 6.29 & 5.68 & 35.70 & 5.72 & 4.18 & 5.55 & 5.49 & 31.98 & 1.60 & 5.37 \\
SD & .20 & .66 & .20 & .60 & .72 & 5.71 & .65 & .94 & .96 & .86 & 9.99 & 1.50 & 1.36 \\
AVE & N.A. & N.A. & N.A. & .61 & .60 & N.A. & .74 & .85 & .81 & .69 & N.A. & N.A. N.A. \\
Square root of AVE & N.A. & N.A. & N.A. & .78 & .77 & N.A. & .86 & .92 & .90 & .83 & N.A. & N.A. N.A. \\
Composite reliability (CR) & N.A. & N.A. & N.A. & .90 & .90 & N.A. & .90 & .95 & .90 & .82 & N.A. & N.A. & N.A. \\
\hline
\end{tabular}

${ }^{*} p<.05$ (two-tailed).

${ }^{* *} p<.01$ (two-tailed).

Notes: For single-item measures, AVE and CR cannot be computed. N.A. = not applicable.

Mardia's normalized estimate indicates significant multivariate kurtosis $(\mathrm{z}=3.799, p<.01)$; we rely on maximum likelihood robust estimation for our confirmatory factor analysis. The indexes suggest adequate fit of the measurement model $\left(\chi^{2}(193)=226.223\right.$, comparative fit index $=$ .979 , Tucker-Lewis index $=.975$, root mean square error of approximation $=.038$, and standardized root mean square residual $=.053)$. All factor loadings are substantive $(>.717)$ and significant $(p<.01)$. There are no cross-loadings, and construct reliabilities range between .82 and .95 , above the recommended threshold (Bagozzi and Yi 1988). Average variances extracted (AVE) are greater than .50, and their square roots exceed the correlations of all construct pairs. Together, these findings indicate the convergent and discriminant validity of our constructs (Fornell and Larcker 1981). Consistent with our conceptualization and previous studies on ambidexterity (e.g., Cao, Gedajlovic, and Zhang 2009; Gibson and Birkinshaw 2004), we multiplied the customer service provision and cross-/up-selling measures to construct a measure for ambidextrous behavior that reflects the nonsubstitutability and interdependence of its elements. Table 1 provides a summary of the descriptive statistics, correlations, AVEs and their square roots, and construct reliabilities of the constructs.

We used Mplus 6.0 to test our hypotheses. This software estimates models involving latent variable interactions with maximum likelihood robust estimation and a version of the latent moderated structural equations method that explicitly considers the type of nonnormality implied by latent variable interactions and provides standard errors robust to nonnormality (Klein and Moosbrugger 2000; Muthén and Muthén 2009). To test our hypotheses, we used a nested model approach. We compared the models with the Satorra-Bentler scaled chi-square difference test, based on the log-likelihood values of the models (Satorra and Bentler 2001).

\section{Results}

We provide an overview of the results in Table 2. Model 1 includes the effects of the control variables, the first-order effects of the variables involved in the two- and three-way interactions, and the effects of ambidextrous behavior on the performance outcomes. We add all two-way interactions in Model 2, which results in improved model fit $\left(\Delta \chi_{\mathrm{SB}}^{2}(5)=\right.$ $11.152, p<.05)$. In Model 3, we insert the three-way interactions. Adding these interaction terms improves model fit significantly $\left(\Delta \chi_{\mathrm{SB}}^{2}(2)=19.314, p<.01\right)$.

In support of $\mathrm{H}_{1}$, the effect of the locomotion orientation on ambidextrous behavior is significant and positive $(b=2.353, p<.05)$. In $\mathrm{H}_{2}$, we predicted that this positive effect would strengthen with increasing levels of assessment orientation. Consistent with our prediction, the locomotion $\times$ assessment orientation interaction is significant and positive $(\mathrm{b}=2.826, p<.05)$. Furthermore, Model 3 reveals a significant, negative three-way interaction with team identification $(b=-2.136, p<.05)$, in support of $\mathrm{H}_{3}$. With Figure 2, we probe further into this three-way interaction. When CSRs' team identification is weak (Panel A), there is a positive interaction between locomotion and assessment orientations. This positive interaction disappears when CSRs strongly identify with their team (Panel B). A comparison of both panels shows that CSRs' locomotion orientation has the most positive impact on ambidextrous behavior when assessment orientation is high and team identification is weak (Panel A).

In support of $\mathrm{H}_{4}$, we find a significant, negative threeway interaction of bounded discretion, locomotion orientation, and assessment orientation $(b=-5.066, p<.01)$. In Figure 3, we depict the positive interaction effect of the two motivational orientations on ambidextrous behavior when the exercise of bounded discretion is low (Panel A). Yet this interaction weakens when the exercise of bounded discretion is high (Panel B). Consistent with 
TABLE 2

Estimated Path Coefficients for Antecedents and Performance Consequences of CSRs' Ambidextrous Behavior

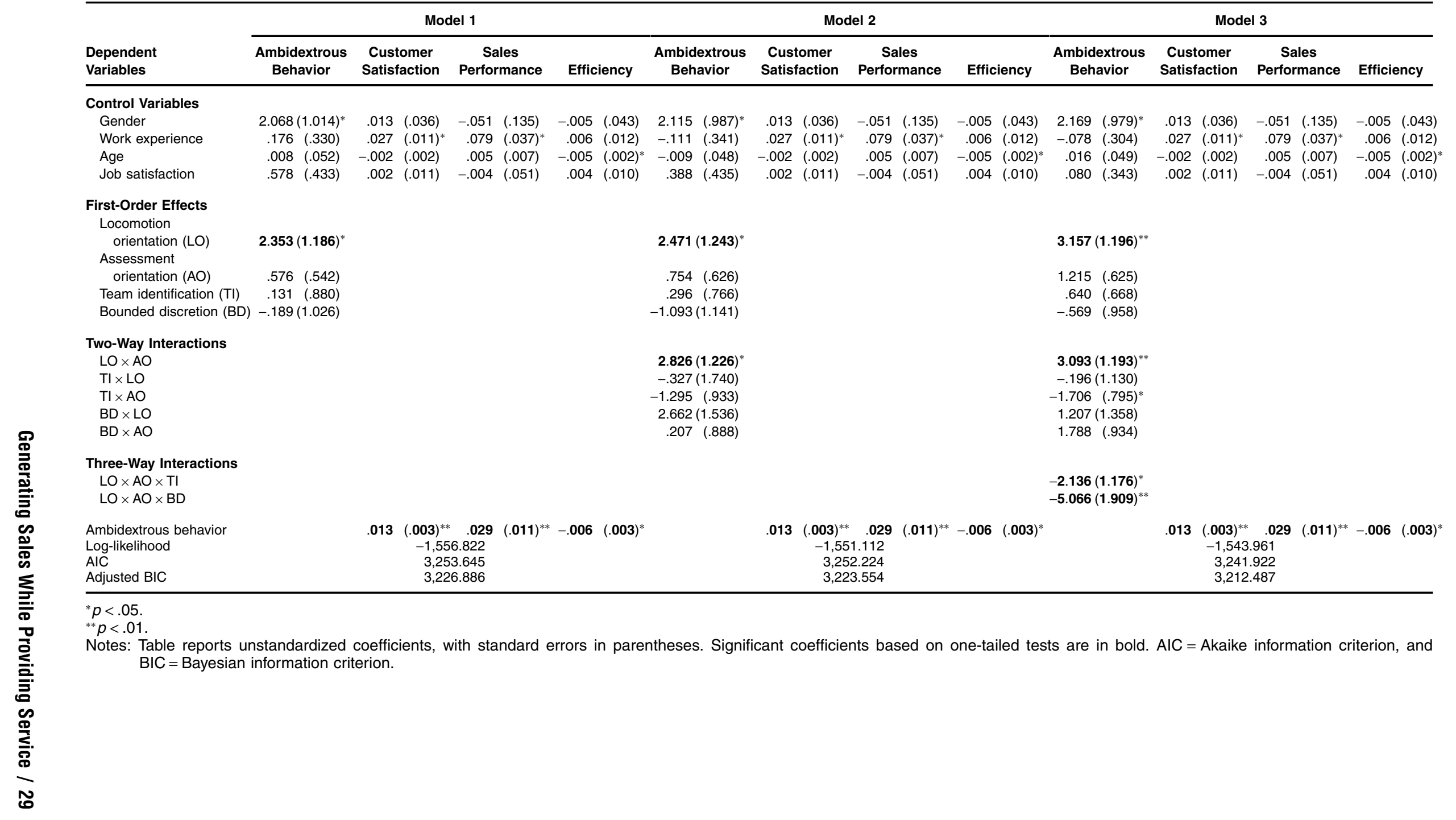


FIGURE 2

The Moderating Effect of Team Identification

A: When CSRs' Team Identification Is Weak

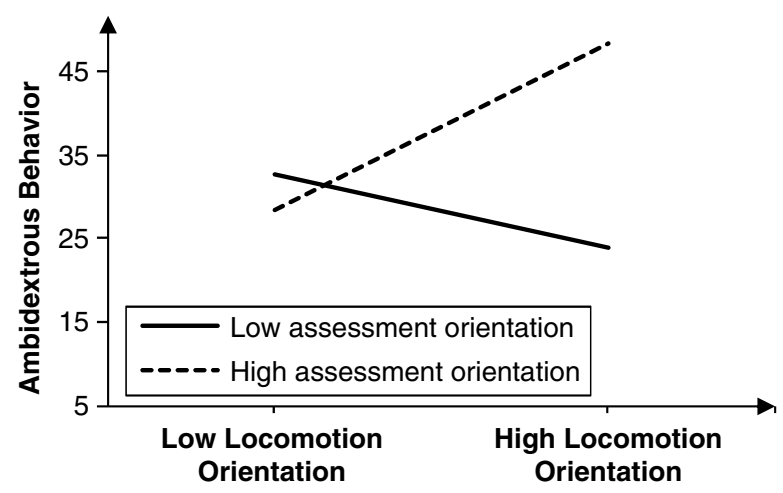

B: When CSRs' Team Identification Is Strong

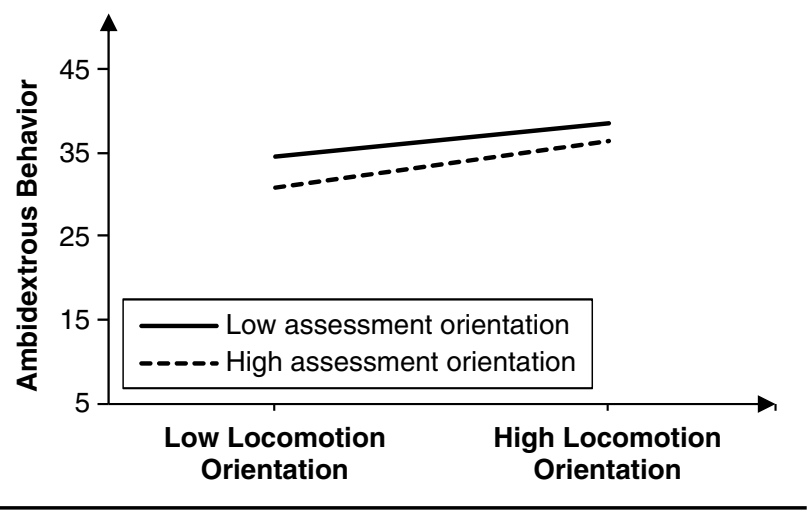

Notes: Figure shows the simple slopes of locomotion orientation at 1.5 standard deviations above and below the means of assessment orientation and team identification. The intercepts of the simple slopes represent male CSRs and would shift by 2.169 for female CSRs.

our expectation, CSRs' locomotion orientation has the most positive effect on ambidextrous behavior when their assessment orientation is high and exercise of bounded discretion is low (Panel A).

In support of $\mathrm{H}_{5}, \mathrm{H}_{6}$, and $\mathrm{H}_{7}$, we find significant, positive effects of ambidextrous behavior on customer satisfaction $(\mathrm{b}=.013, p<.01)$ and sales performance $(\mathrm{b}=.029, p<.01)$ and a significant negative effect on efficiency $(b=-.006$, $p<.05)$. Because the effects of our multiplicative ambidexterity measure as an exogenous variable are potentially biased (Edwards 1994), we explicitly estimated the interaction effects of customer service provision and cross-/ up-selling on the performance outcomes while controlling for their main effects. Table 3 shows the results. We find that adding the two-way interaction of customer service provision and cross-/up-selling significantly improves model fit $\left(\Delta \chi_{\mathrm{SB}}^{2}(3)=17.788, p<.01\right)$. The results also reveal significant interaction effects of customer service provision and cross-/up-selling on customer satisfaction $(\mathrm{b}=.174, p<.01)$, sales performance $(\mathrm{b}=.548, p<.05)$,
FIGURE 3

The Moderating Effect of CSRs' Exercise of Bounded Discretion

A: When CSRs' Exercise of Bounded Discretion Is Low

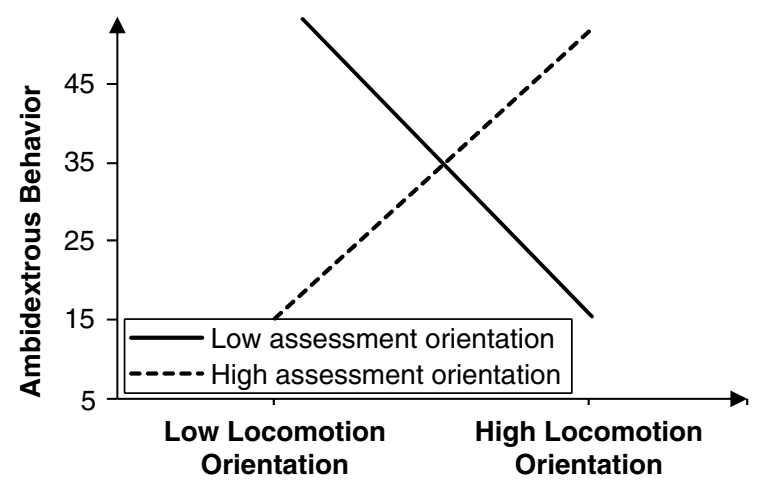

B: When CSRs' Exercise of Bounded Discretion is High

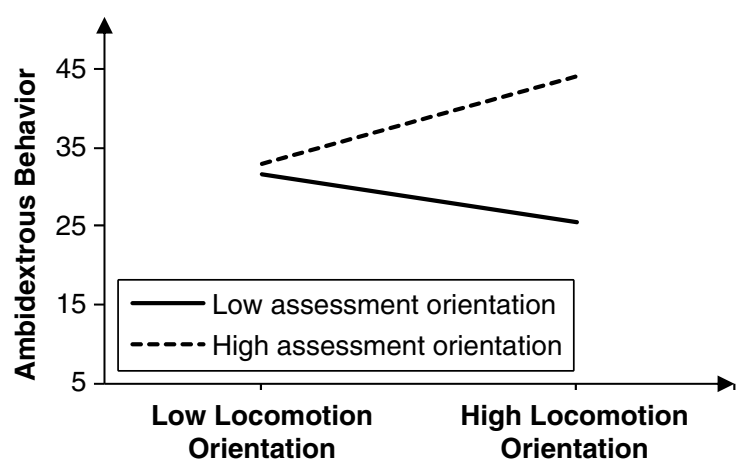

Notes: Figure shows the simple slopes of locomotion orientation at 1.5 standard deviations above and below the means of assessment orientation and bounded discretion. The intercepts of the simple slopes represent male CSRs and would shift by 2.169 for female CSRs.

and efficiency $(\mathrm{b}=-.121, p<.05)$, providing strong support for $\mathrm{H}_{5}, \mathrm{H}_{6}$, and $\mathrm{H}_{7}$.

With Figure 4, we probe further into these interaction effects on customer satisfaction and sales performance to depict the nature of complementarity between customer service provision and cross-/up-selling. Panel A illustrates that high levels of cross-/up-selling augment the effect of customer service provision on customer satisfaction. Similarly, Panel B shows that cross-/up-selling has a strong positive effect on sales performance when customer service provision is high. Yet, at low customer service provision levels, cross-/up-selling tends to harm sales performance. Together, the results in Table 3 and Figure 4 support our expectation that customer service provision and cross-/up-selling enhance each other in terms of effectiveness for customer satisfaction and sales performance.

Given the relatively small sample size for the estimation of latent variable interactions, we conducted hierarchical ordinary least squares regression analyses to verify the robustness of our findings. We find that the pattern and 
TABLE 3

Interaction Effects of Customer Service Provision and Cross-/Up-Selling on Customer Satisfaction, Sales Performance, and Efficiency

\begin{tabular}{|c|c|c|c|c|c|c|}
\hline $\begin{array}{l}\text { Dependent } \\
\text { Variables }\end{array}$ & $\begin{array}{l}\text { Customer } \\
\text { Satisfaction }\end{array}$ & $\begin{array}{c}\text { Sales } \\
\text { Performance }\end{array}$ & Efficiency & $\begin{array}{l}\text { Customer } \\
\text { Satisfaction }\end{array}$ & $\begin{array}{c}\text { Sales } \\
\text { Performance }\end{array}$ & Efficiency \\
\hline \multicolumn{7}{|l|}{ Control Variables } \\
\hline Gender & $.024(.035)$ & $-.061(.136)$ & $-.011(.042)$ & $.036(.035)$ & $-.018(.129)$ & $-.020(.042)$ \\
\hline Work experience & $.026(.010)^{*}$ & $.079(.037)^{*}$ & .007 (.012) & $.027(.010)^{* *}$ & $.082(.036)^{*}$ & $.006(.012)$ \\
\hline Age & $-.001(.002)$ & $.005(.007)$ & $-.006(.002)^{* *}$ & $-.001(.002)$ & $.006(.006)$ & $-.006(.002)^{* *}$ \\
\hline Job satisfaction & $.008(.011)$ & $-.008(.051)$ & $.001(.011)$ & $.010(.011)$ & $-.002(.050)$ & $-.001(.010)$ \\
\hline \multicolumn{7}{|l|}{ First-Order Effects } \\
\hline $\begin{array}{l}\text { Customer service } \\
\text { provision (CSP) }\end{array}$ & $.173(.026)^{* *}$ & $.149(.109)$ & $-.085(.034)^{*}$ & $.137(.029)^{* *}$ & $.022(.132)$ & $-.058(.036)$ \\
\hline $\begin{array}{l}\text { Cross-/up-selling } \\
\text { (CUS) }\end{array}$ & $.030(.031)$ & $.261(.109)^{*}$ & $-.006(.026)$ & $.029(.030)$ & $.254(.112)^{*}$ & $-.006(.028)$ \\
\hline \multirow{2}{*}{\multicolumn{4}{|c|}{$\begin{array}{l}\text { Two-Way Interaction } \\
\text { CSP } \times \text { CUS }\end{array}$}} & & & \\
\hline & & & & $.174(.053)^{* *}$ & $.548(.307)^{*}$ & $-.121(.067)^{*}$ \\
\hline $\begin{array}{l}\text { Log-likelihood } \\
\text { AIC }\end{array}$ & & $\begin{array}{r}-1,352.789 \\
2,833.579\end{array}$ & & & $\begin{array}{r}-1,345.899 \\
2,825.799\end{array}$ & \\
\hline Adjusted BIC & & $2,809.114$ & & & $2,800.187$ & \\
\hline
\end{tabular}

direction of significant coefficients are nearly identical, in support of our hypotheses. ${ }^{3}$

\section{Discussion and Implications}

Considering the challenges that managers face in their effort to create conditions conducive to CSRs' successful servicesales alignment, as well as the prevalence of employee requirements for ambidextrous behavior, it is surprising that individual-level ambidexterity has not been investigated more systematically (Raisch et al. 2009). Our study addresses this theoretically and managerially relevant gap by investigating antecedents and performance consequences of CSRs' ambidextrous behavior in relation to the pursuit of service and sales goals.

\section{Theoretical Discussion}

Employee-level ambidextrous behavior. Whereas prior research has focused on ambidexterity at organizational

\footnotetext{
${ }^{3}$ We conducted four hierarchical ordinary least squares regression analyses. We regressed ambidextrous behavior on the antecedents and control variables and then entered higher-order terms in separate steps: locomotion orientation $(\beta=.217, p<.05)$, locomotion $\times$ assessment orientation $(\beta=.199, p<.05)$, three-way interactions with team identification $(\beta=-.172, \mathrm{p}<.05)$, and bounded discretion $(\beta=-.268, p<.05)\left(\mathrm{R}^{2}=.285\right)$. In the other regression analyses, we regressed each performance measure on the control variables, customer service provision, and cross-/upselling in the first step and ambidextrous behavior in the second step: the effects of ambidextrous behavior on customer satisfaction: $\beta=.256, p<.01\left(\mathrm{R}^{2}=.299\right)$, sales performance: $\beta=.183$, $p<.05\left(\mathrm{R}^{2}=.132\right)$, and efficiency: $\beta=-.158, p<.10\left(\mathrm{R}^{2}=.152\right)$.
}

levels, our study advances the understanding of employeelevel ambidexterity. Theoretical work on ambidexterity regards its constituent dimensions as mutually exclusive at the individual level (Gupta, Smith, and Shalley 2006; March 1991); our review of the literature suggests that they are not completely incompatible in the context of CSRs' service-sales alignment. In support of our proposition, Table 1 shows that customer service provision and cross-/up-selling are essentially uncorrelated. Employees can engage in nonnegligible levels of ambidextrous behavior; $10 \%$ of our sample scored in the upper $15 \%$ on the measure of ambidextrous behavior. Recent empirical research also has indicated that managers can engage in ambidextrous behavior by addressing disparate task demands during a one-year period (Mom, Van den Bosch, and Volberda 2009), and our study further highlights a context in which employees simultaneously engage in seemingly conflicting tasks and/or switch between them at "minute intervals" to become ambidextrous. The prevalence and diversity of contexts in which people are required to act ambidextrously leaves much to be clarified regarding how ambidexterity becomes manifest at the employee level (e.g., cycling, simultaneity, or both), and why and when it does so.

Facilitators of ambidextrous behavior. Previous research has focused on organizational and contextual factors that may enable and support employees to become ambidextrous (e.g., Gibson and Birkinshaw 2004; Mom, Van den Bosch, and Volberda 2009). Yet, eventually, employees need to tackle the self-regulatory and motivational challenge posed by the pursuit of seemingly conflicting goals on their own. Our study underscores the indispensable role of motivational orientations with regard to how to pursue goals as an explanation of ambidextrous behavior. In particular, our results show a positive effect of the locomotion orientation on CSRs' ambidextrous behavior. This effect becomes 
FIGURE 4

Interaction Effects of Customer Service Provision and Cross-/Up-Selling on Customer Satisfaction and Sales Performance

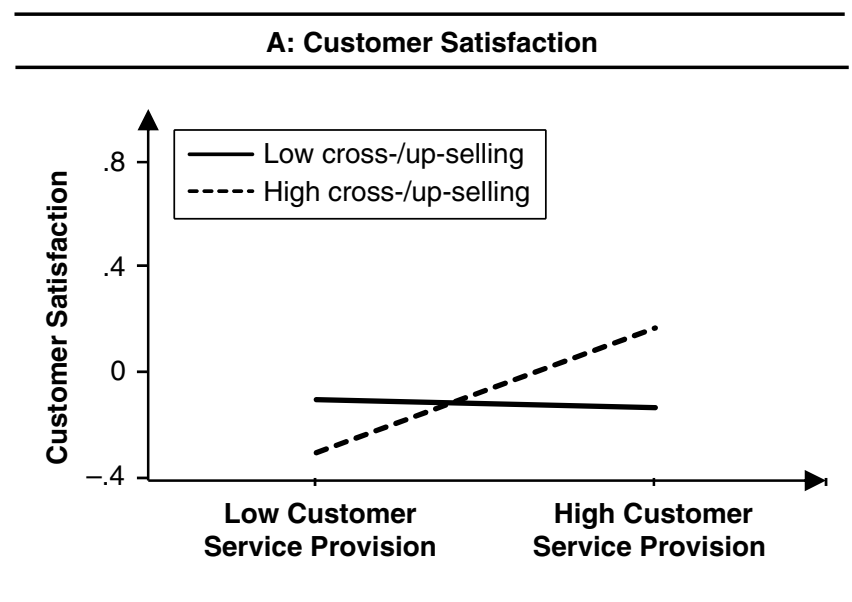

B: Sales Performance

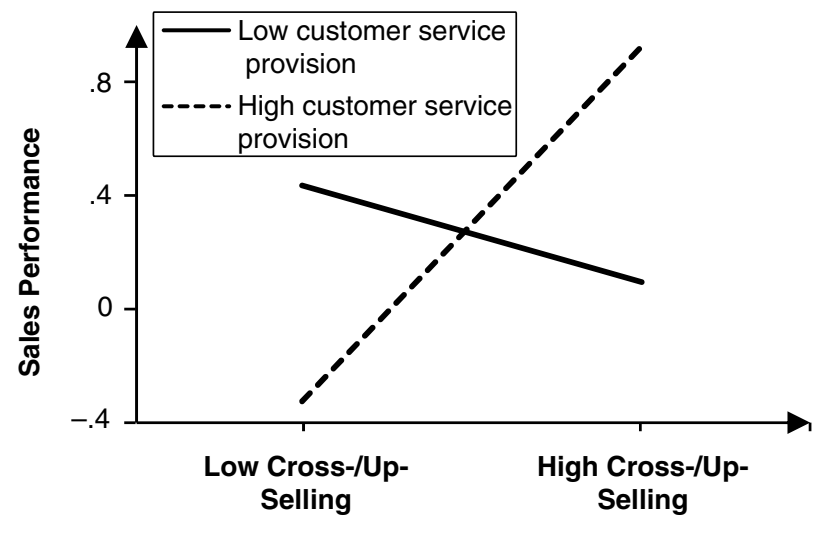

Notes: Figure shows the simple slopes of customer service provision (Panel A) and cross-/up-selling (Panel B) at 1.5 standard deviations above and below the means of cross-/up-selling (Panel A) and customer service provision (Panel B).

considerably enhanced when CSRs are also highly assessment oriented. Thus, the joint presence of these motivations to experience movement and "do the right thing" is conducive to CSRs' ambidextrous behavior. Conceptual work cites the importance of the motivation to pursue conflicting activities and goals (Mom, Van den Bosch, and Volberda 2009). Our study highlights that the locomotion and assessment orientations jointly embody such motivational capacity for CSRs' pursuit of service and sales goals. In addition, previous empirical research by Kruglanski and colleagues (2000, 2007) highlights the relevance of these motivational orientations for employees who need to master challenging, increasingly complex, and changing job demands. We therefore expect the valuable interaction of these orientations, with their joint emphasis on "just do the right thing," to generalize to other contexts in which people must act ambidextrously. Other factors might facilitate ambidextrous behavior. For example, our control variables suggest that gender has a significant impact (see Table 2). Post hoc analyses reveal that female CSRs engage more in ambidextrous behavior $(\mathrm{t}(117)=-2.546, p<.05)$ and cross-/ up-selling $(\mathrm{t}(117)=-3.132, p<.01)$. Our study of antecedents of individual-level ambidextrous behavior invites further extension studies.

Structural contingencies as moderators. Our study reveals that CSRs' responses to typical structural call center controls in terms of team identification and bounded discretion create motivational conditions that impair the functionality of the motivational orientations for ambidextrous behavior. These findings underscore the importance of considering the impact of contextually relevant factors on the motivational capacity to self-regulate toward ambidextrous behavior at the personal level.

First, whereas extant literature largely highlights the positive implications of organizational and work group identification for firms (see Ashforth, Harrison, and Corley 2008), our study reveals that strong team identification impairs the effective interplay of CSRs' locomotion and assessment orientations, making ambidextrous behavior less likely. When team identification is weak (Figure 2, Panel A), the locomotion orientation positively affects ambidextrous behavior for high-assessment-oriented CSRs. Yet, when team identification is strong, convergent thinking and conformity to shared consensus reduce active deliberation and critical questioning. Accordingly, the assessment orientation loses its virtue, and the positive impact of the locomotion orientation declines, if not disappears (Figure 2, Panel B). Although these findings highlight a detrimental effect of team identification, we also note that strong team identification seems to neutralize the negative effect of the locomotion orientation for low-assessment-oriented CSRs. The psychological attachment to the team and the resulting desire to enhance the team's well-being make task engagement purposeful but fail to guide a locomotion orientation toward ambidextrous behavior. However, in the case team members identify specifically with the team as an ambidextrous unit, with the consensus being that every member should be engaged, the results could be quite opposite, which additional research would need to explore.

Second, we find an impairing effect of high bounded discretion, as the reduced cognitive effort involved in the routinized flow of activity inhibits the functionality of an assessment orientation. Only when the exercise of bounded discretion is low (Figure 3, Panel A) does the assessment orientation purposefully guide high-locomotionoriented CSRs' task engagement in the direction of their service and sales goals, leading to ambidextrous behavior. When CSRs exercise high levels of bounded discretion (Figure 3, Panel B), the assessment orientation becomes ineffective, and the ambidexterity-enhancing effect of the locomotion orientation disappears. However, a high level of bounded discretion also seems to buffer against a negative impact of the locomotion orientation when assessment orientation is low. Routinized compliance with organizational prescriptions and routines seems to channel high-locomotion-oriented CSRs' task engagement, but in a way seemingly unrelated to ambidextrous behavior. Thus, locomotion and assessment orientations operate at full force only at low levels of bounded discretion.

Accordingly, our study highlights the intricacy involved in shaping ambidextrous behavior at the employee level, 
as well as the importance of considering how employees' motivational orientations interact with their responses to proximal work environment characteristics. We focus on team identification and the exercise of bounded discretion as CSRs' responses to prevalent call center characteristics; therefore, our study invites further research to study the role of other environmental aspects. An important extension of our study would be to examine factors that might compensate for low levels of the assessment or locomotion orientation and foster individual ambidextrous behavior. For example, when explicit reward and compensation plans are in place and structured in the right way, a locomotion orientation in the absence of assessment concerns might become functional to promote goal attainment and ambidexterity.

Performance consequences of ambidextrous behavior. To the best of our knowledge, our study is the first to investigate the validity of the ambidexterity-performance tenet at the employee level. Our findings reveal the importance of considering various performance parameters for studying the effects of employees' ambidextrous behavior. We find that CSRs' ambidextrous behavior leads to superior customer satisfaction and sales performance, highlighting the complementary effects of customer service provision and cross-/ up-selling. However, ambidextrous behavior also results in efficiency losses for CSRs, reflecting the apparent tensions among revenue expansion, quality, and efficiency that previous studies have highlighted for macro-organizational levels (Marinova, Ye, and Singh 2008; Rust, Moorman, and Dickson 2002). Does this finding provide counterevidence for the validity of the tenet that ambidexterity leads to superior performance? We think not. First, a post hoc analysis with standardized coefficients reveals that ambidextrous behavior increases customer satisfaction $(\mathrm{B}=.361$, $p<.01)$ and sales performance $(\mathrm{B}=.249, p<.01)$ more than it decreases efficiency $(\mathrm{B}=-.163, p<.05)$. Thus, the overall performance effect is positive, which confirms the validity of the ambidexterity-performance tenet at the employee level. Second, the gains in customer satisfaction and sales performance potentially outweigh the efficiency losses at the firm level because customer satisfaction and cross-/up-selling result in positive long-term benefits, such as enhanced customer-firm relationships (e.g., Bolton 1998). Third, a successful service-sales alignment could lead to efficiency gains at the firm level, greater than the sum of the CSRs' efficiency losses, because it allows for reduced investments in traditional cross-/up-selling channels (e.g., outbound call centers), as well as capitalization on customerinitiated touch points. Overall, our discussion suggests that individual ambidextrous behavior can have positive performance implications for various organizational levels. Further research should study the levels and conditions at which the performance-enhancing effects of employee-level ambidexterity unfold.

\section{Limitations}

We recognize that our study is not without limitations, some of which highlight avenues for further research in addition to those already outlined. Our empirical study is based on a relatively small sample of CSRs, which may limit the generalizability of our findings. Yet a comparison of our sample profile with those in other studies and industry norms suggests the representativeness of our sample. Although small samples tend to reduce statistical power and inflate Type II errors, we still find strong support for all our theory-grounded hypotheses. Furthermore, we conducted our empirical study in a single company setting and therefore ruled out any effects based on company differences, but this study should be replicated to generalize our findings. Our effort to collect data in two call center sites and develop the measurement scales with a separate study should alleviate some concerns about single-domain effects. Another avenue for research is the study of CSRs' ambidextrous behavior in different after-sales support settings. We focused on one-time customer-CSR interactions; studying ambidextrous behavior in service relationships in which customers repeatedly interact with the same CSR would be worthwhile. Further research might also explore the nature of the service-sales alignment in industries that market highly complex products, such as turbines, in which the complexity of service and selling might be increased to such an extent that it shifts the organizational level at which ambidexterity can be pursued. Another promising extension of our study could explore how customer- or relationshiprelated factors, such as reciprocity and trust, interact with the variables in our model.

\section{Managerial Implications}

For managers who want to tap the full potential of a service-sales alignment in customer service channels, our study offers useful insights and several recommendations. The commonly cited observation that CSRs view customer service provision as incommensurate with selling seems to reflect their struggle with conflicting task demands. An awareness of the conflicting demands that CSRs face should encourage service-sales alignment. Our study of motivational orientations explains some of the heterogeneity observed in CSRs' ability to convert service calls to cross-/ up-selling. During personnel selection, call centers may find it valuable to assess the motivational orientations of their job candidates. Because CSRs who are locomotion and assessment oriented engage in more ambidextrous behavior, they seem the best-suited candidates for a service-sales job. Such a person-job fit has additional positive outcomes, such as job satisfaction (Kristof-Brown, Zimmerman, and Johnson 2005), which can increase customer satisfaction (Harter, Schmidt, and Hayes 2002). In designing CSR training modules, it seems advisable to stimulate self-regulation skills. In training sessions, CSRs should be given the opportunity to elaborate on their personal motivations and to reflect on and discuss how they invest effort and attempt to meet performance standards in the context of service-sales alignment. Furthermore, assessing the motivational orientations of already-employed CSRs would provide valuable information for intelligent routing. Customers with higher cross-buying probability could be routed to CSRs with high locomotion and assessment orientations; those with low cross-buying potential should talk with CSRs who are less successful at aligning their service and sales. Such routing might mitigate efficiency losses for call centers.

Our study also reveals that CSRs' responses to typical call center characteristics impair the valuable interplay of 
locomotion and assessment orientations, which complicates the creation of conditions conducive to successful alignment. Regarding the negative effect of team identification, we consider the idea of abolishing team structures or reducing team-building efforts in call centers premature. Teams have administrative advantages and offer social and task support to team members. Interventions to prevent overidentification may be valuable however. When observing strong team consensus and conformity, team managers may want to spur critical reflection, divergent thinking, and questioning among team members during regular team meetings or ad hoc individual "stop-and-think" sessions. Managers could stimulate teams to develop a team norm that highly values active deliberation of alternatives. The exercise of bounded discretion also has a negative effect. In service-only call centers, a certain degree of bounded discretion seems appropriate for the relatively standardized nature of service offerings (Kelley 1993). However, service-sales alignment requires greater latitude and more customized service encounters, so encouraging more appropriate forms of discretion among CSRs, which also allow for critical thinking and comparative evaluations, is worthwhile.

Finally, our study provides some encouraging findings regarding the performance implications of service-sales alignment. When CSRs focus on both customer service provision and cross-/up-selling, they produce increased customer satisfaction and revenues. The satisfaction-enhancing effect of aligned sales and customer service provision is noteworthy and helps prove that the fear that sales efforts may put customers off is unfounded (CSO Insights 2007; Eichfeld, Morse, and Scott 2006). However, the resulting efficiency losses imply the need for higher staff levels, which lead to more costs for inbound call centers. Multiskill call centers, which combine inbound and traditional outbound cross-/up-selling, might offset such costs by revising their staffing levels for outbound activities. Nevertheless, the traditional focus on efficiency as the key performance parameter in inbound call centers is an antithesis to the goals firms try to achieve with service-sales alignment. Firms should reconsider a strong focus on efficiency because increased customer satisfaction and successful cross-/up-selling may lead to long-term benefits, such as enhanced customer retention and loyalty. When assessing the profitability of a service-sales alignment, firms should consider long-term implications in addition to immediately visible efficiency losses.

\section{Appendix Overview of Measures}

All items were measured with seven-point Likert scales ranging from "strongly disagree" to "strongly agree."

\section{Customer Service Provision (New scale)}

During conversation with customers, ...

-I usually try to calm complaining customers, so that we can jointly handle their complaints about their products.

-I usually provide solutions to customers' concerns related to the products they currently own.
-Having identified the customers' exact problem with their products, I solve it in a reliable way.

-I usually listen attentively to customers in order to take appropriate action to handle their concerns regarding their products.

-I usually pay attention to the customers' questions about their products to answer them correctly.

-Making sure that I fully understand the reason why the customers contact me allows me to better help them with their questions and concerns regarding their products.

\section{Cross-/Up-Selling (New scale)}

During conversation with customers, ...

-I usually explore potential matches between the customers' needs and the features of a product which they do not currently own.

-I usually gather as much customer information as possible to offer a suitable product to customers.

-I usually try to identify good ways of familiarizing customers with another product that can satisfy their needs.

-I usually ask questions to assess whether the customers would be willing to buy an additional product.

-I hardly neglect a good opportunity to advise customers of a product which they could benefit from.

-I usually offer an additional product which meets the customers' needs best.

\section{Locomotion Orientation (Kruglanski et al. 2000)}

Parcel 1

-I feel excited just before I am about to reach a goal.

-By the time I accomplish a task, I already have the next one in mind.

-I am a "workaholic."

Parcel 2

-When I decide to do something, I can't wait to get started.

-Most of the time my thoughts are occupied with the task I wish to accomplish.

-I enjoy actively doing things, more than just watching and observing.

Parcel 3

-I am a "doer."

-When I get started on something, I usually persevere until I finish it.

-I don't mind doing things even if they involve extra effort.

\section{Assessment Orientation (Kruglanski et al. 2000)}

Parcel 1

-I like evaluating other people's plans.

-I am a critical person.

-I often critique work done by myself or others.

Parcel 2

-I often feel that I am being evaluated by others.

-When I meet a new person I usually evaluate how well he or she is doing on various dimensions (e.g., looks, achievements, social status, clothes).

-I spend a great deal of time taking inventory of my positive and negative characteristics. 


\section{Parcel 3}

-I am very self-critical and self-conscious about what I am saying.

-I often think that other people's choices and decisions are wrong.

-I often compare myself with other people.

\section{Team Identification (Adapted from Mael and Ashforth 1992)}

Parcel 1

-My team's success is my success.

-When I talk about my team, I usually say "we" rather than "they."

-When someone praises my team, it feels like a personal compliment.

Parcel 2

-I am very interested in what others think about my team.
-When someone criticizes my team, it feels like a personal insult.

\section{Bounded Discretion (Kelley, Longfellow, and Malehorn 1996)}

Parcel 1

-I use routine procedures to complete my job tasks when possible.

-I consult my colleagues for ways to complete my job tasks when necessary.

-I consult organizational manuals for the right way to complete my job tasks when necessary.

Parcel 2

-I try to develop a routine for each of the typical duties involved in my job.

-I decide how to perform my job duties based on training I have received.

\section{REFERENCES}

-Adler, Paul S., Barbara Goldoftas, and David I. Levine (1999), "Flexibility versus Efficiency? A Case Study of Model Changeovers in the Toyota Production System," Organization Science, 10 (1), 43-68.

-Aksin, O. Zeynep, Mor Armony, and Vijay Mehrotra (2007), "The Modern Call Center: A Multi-Disciplinary Perspective on Operations Management Research," Production and Operations Management, 16 (6), 665-88.

_ and Patrick T. Harker (1999), "To Sell or Not to Sell: Determining the Trade-Offs Between Service and Sales in Retail Banking Phone Centers," Journal of Service Research, 2 (1), 19-33.

-Ashforth, Blake E., Spencer H. Harrison, and Kevin G. Corley (2008), "Identification in Organizations: An Examination of Four Fundamental Questions," Journal of Management, 34 (3), 325-74.

— and Fred Mael (1989), "Social Identity Theory and the Organization," Academy of Management Review, 14 (1), 20-39.

-Avnet, Tamar and E. Tory Higgins (2003), "Locomotion, Assessment, and Regulatory Fit: Value Transfer from 'How' to 'What,'” Journal of Experimental Social Psychology, 39 (5), 525-30.

Bagozzi, Richard P. and Jeffrey R. Edwards (1998), "A General Approach for Representing Constructs in Organization Research," Organizational Research Methods, 1 (1), 45-87.

_ and Todd F. Heatherton (1994), “A General Approach to Representing Multifaceted Personality Constructs: Application to State Self-Esteem," Structural Equation Modeling, 1 (1), $35-67$.

— and Youjae Yi (1988), "On the Evaluation of Structural Equation Models," Journal of the Academy of Marketing Science, 16 (1), 74-97.

- Balcetis, Emily and David Dunning (2006), "See What You Want to See: Motivational Influences on Visual Perception," Journal of Personality and Social Psychology, 91 (4), 612-25.

Bitner, Mary Jo, Bernard H. Booms, and Mary Stanfield Tetreault (1990), "The Service Encounter: Diagnosing Favorable and Unfavorable Incidents," Journal of Marketing, 54 (January), $71-84$.
Bolton, Ruth N. (1998), "A Dynamic Model of the Duration of the Customer's Relationship with a Continuous Service Provider: The Role of Satisfaction," Marketing Science, 17 (1), 45-65.

Brady, Michael K. and Joseph Cronin Jr. (2001), "Some New Thoughts on Conceptualizing Perceived Service Quality: A Hierarchical Approach," Journal of Marketing, 65 (July), 34-49.

Cao, Qing, Eric Gedajlovic, and Hongping Zhang (2009), "Unpacking Organizational Ambidexterity: Dimensions, Contingencies, and Synergistic Effects," Organization Science, 20 (4), 781-96.

Carver, Charles S. and Michael F. Scheier (2010), "SelfRegulation of Action and Affect," in Handbook of Self-Regulation: Research, Theory, and Applications, 2d ed., K.D. Vohs and R.F. Baumeister, eds. New York: The Guilford Press, 3-21.

Coffman, Donna L. and Robert C. MacCallum (2005), "Using Parcels to Convert Path Analysis Models Into Latent Variable Models," Multivariate Behavioral Research, 40 (2), 235-59.

CSO Insights (2007), Sales Performance Report 2007: Call Center Marketing \& Sales Optimization Study, Jim Dicky and Berry Trailer, eds. Boulder: CSO Insights.

Deery, Stephen, Roderick Iverson, and Janet Walsh (2002), "Work Relationships in Telephone Call Centres: Understanding Emotional Exhaustion and Employee Withdrawal," Journal of Management Studies, 39 (4), 471-96.

$\checkmark$ Dutton, Jane E., Janet M. Dukerich, and Celia V. Harquail (1994), "Organizational Images and Member Identification," Administrative Science Quarterly, 39 (2), 239-63.

-Edwards, Jeffrey R. (1994), “The Study of Congruence in Organizational Behavior Research: Critique and a Proposed Alternative," Organizational Behavior and Human Decision Processes, 58 (1), 51-100.

Eichfeld, Andy, Timothy D. Morse, and Katherine W. Scott (2006), "Using Call Centers to Boost Revenue," The McKinsey Quarterly, (May), 1-7.

Evans, Kenneth R., Todd J. Arnold, and John A. Grant (1999), "Combining Service and Sales at the Point of Customer Contact: A Retail Banking Example," Journal of Service Research, 2 (1), 34-49. 
Fitzsimons, Gráinne M. and John A. Bargh (2004), "Automatic Self-Regulation," in Handbook of Self-Regulation: Research, Theory, and Applications, R.F. Baumeister and K.D. Vohs, eds. New York: The Guilford Press, 151-70.

-Fornell, Claes and David F. Larcker (1981), "Evaluating Structural Equation Models with Unobservable Variables and Measurement Error," Journal of Marketing Research, 18 (February), $39-50$.

Gibson, Christina and Julian Birkinshaw (2004), "The Antecedents, Consequences, and Mediating Role of Organizational Ambidexterity," Academy of Management Journal, 47 (April), 209-226.

- Günes, Evrim D., O. Zeynep Aksin, E. Lerzan Örmeci, and S. Hazal Özden (2010), "Modeling Customer Reactions to Sales Attempts: If Cross-Selling Backfires," Journal of Service Research, 13 (2), 168-83.

Gupta, Anil K., Ken G. Smith, and Christina E. Shalley (2006), "The Interplay Between Exploration and Exploitation," Academy of Management Journal, 49 (4), 693-706.

Gwinner, Kevin P., Mary Jo Bitner, Stephen W. Brown, and Ajith Kumar (2005), "Service Customization Through Employee Adaptiveness," Journal of Service Research, 8 (2), 131-48.

-Harter, James K., Frank L. Schmidt, and Theodore L. Hayes (2002), "Business-Unit-Level Relationship Between Employee Satisfaction, Employee Engagement, and Business Outcomes: A Meta-Analysis," Journal of Applied Psychology, 87 (2), 268-79.

-Haslam, Alexander S., Clair Powell, and John C. Turner (2000), "Social Identity, Self-Categorization, and Work Motivation: Rethinking the Contribution of the Group to Positive and Sustainable Organizational Outcomes," Applied Psychology: An International Review, 49 (3), 319-39.

-Hennig-Thurau, Thorsten, Markus Groth, Michael Paul, and Dwayne D. Gremler (2006), "Are All Smiles Created Equal? How Emotional Contagion and Emotional Labor Affect Service Relationships," Journal of Marketing, 70 (July), 58-73.

Higgins, E. Tory, Arie W. Kruglanski, and Antonio Pierro (2003), "Regulatory Mode: Locomotion and Assessment as Distinct Orientations," in Advances in Experimental Social Psychology, M.P. Zanna, ed. New York: Academic Press, 293-344.

International Customer Management Institute (2007), "Call Center Management Review: 2007 Call Center Cross-Selling Survey Report," International Customer Management Institute, CMP Media.

-Kelley, Scott (1993), "Discretion and the Service Employee," Journal of Retailing, 69 (1), 104-126.

— Timothy Longfellow, and Jack Malehorn (1996), "Organizational Determinants of Service Employees' Exercise of Routine, Creative, and Deviant Discretion," Journal of Retailing, 72 (2), 135-57.

-Klein, Andreas and Helfried Moosbrugger (2000), "Maximum Likelihood Estimation of Latent Interaction Effects with the LMS Method," Psychometrika, 65 (4), 457-74.

-Kristof-Brown, Amy L., Ryan D. Zimmerman, and Erin C. Johnson (2005), "Consequences of Individuals' Fit at Work: A MetaAnalysis of Person-Job, Person-Organization, Person-Group, and Person-Supervisor Fit," Personnel Psychology, 58 (2), 281-342.

Kruglanski, Arie W., Edward Orehek, Tory E. Higgins, Antonio Pierro, and Idit Shalev (2010), "Modes of Self-Regulation: Assessment and Locomotion as Independent Determinants in Goal Pursuit," in Handbook of Personality and Self-Regulation, R.H. Hoyle, ed. Malden, MA: Blackwell-Wiley, 375-402.
Antonio Pierro, Tory E. Higgins, and Dora Capozza (2007), “' 'On the Move' or 'Staying Put': Locomotion, Need for Closure, and Reactions to Organizational Change," Journal of Applied Social Psychology, 37 (6), 1305-1340.

—, Erik P. Thompson, Tory E. Higgins, M. Nadir Atash, Antonio Pierro, James Y. Shah, and Scott Spiegel (2000), “To 'Do the Right Thing' or to 'Just Do It': Locomotion and Assessment as Distinct Self-Regulatory Imperatives," Journal of Personality and Social Psychology, 79 (5), 793-815.

Lang, Peter J., Margaret M. Bradley, and Bruce N. Cuthbert (1997), "Motivated Attention: Affect, Activation, and Action," in Attention and Orienting, P.J. Lang, R.F. Simons, and M.T. Balaban, eds. Mahwah, NJ: Lawrence Erlbaum Associates, 95-135.

Levinthal, D.A. and James G. March (1993), "The Myopia of Learning," Strategic Management Journal, 14 (Winter), 95-112.

-Mael, Fred and Blake E. Ashforth (1992), "Alumni and Their Alma Mater: A Partial Test of the Reformulated Model of Organizational Identification," Journal of Organizational Behavior, 13 (2), 103-123.

-March, James G. (1991), "Exploration and Exploitation in Organizational Learning," Organization Science, 2 (1), 71-87.

and Herbert A. Simon (1958), Organizations. New York: John Wiley \& Sons.

Marinova, Detelina, Jun Ye, and Jagdip Singh (2008), "Do Frontline Mechanisms Matter? Impact of Quality and Productivity Orientations on Unit Revenue, Efficiency, and Customer Satisfaction," Journal of Marketing, 72 (March), 28-45.

-Markides, Costas (2007), "In Search of Ambidextrous Professors," Academy of Management Journal, 50 (4), 762-68.

Mom, Tom J.M., Frans A.J. van den Bosch, and Henk W. Volberda (2009), 'Understanding Variation in Managers' Ambidexterity: Investigating Direct and Interaction Effects of Formal Structural and Personal Coordination Mechanisms," Organization Science, 20 (4), 812-28.

Muthén, Linda K. and Bengt O. Muthén (2009), Mplus User's Guide, 5th ed. Los Angeles: Muthén \& Muthén.

Netemeyer, Richard G., William O. Bearden, and Subhash Sharma (2003), Scaling Procedures: Issues and Applications. Thousand Oaks, CA: Sage Publications.

Periatt, Jeffrey A., Stephen A. LeMay, and Subhra Chakrabarty (2004), "The Selling Orientation-Customer Orientation (SOCO) Scale: Cross-Validation of the Revised Version," Journal of Personal Selling \& Sales Management, 24 (1), 49-54.

-Pierro, Antonio, Arie W. Kruglanski, and E. Tory Higgins (2006), "Regulatory Mode and the Joys of Doing: Effects of 'Locomotion' and 'Assessment' on Intrinsic and Extrinsic TaskMotivation,' European Journal of Personality, 20 (5), 355-75.

_ Susanne Leder, Lucia Mannetti, Tory E. Higgins, Arie W. Kruglanski, and Antonio Aiello (2008), "Regulatory Mode Effects on Counterfactual Thinking and Regret," Journal of Experimental Social Psychology, 44 (2), 321-29.

-Plouffe, Christopher R., John Hulland, and Trent Wachner (2009), "Customer-Directed Selling Behaviors and Performance: A Comparison of Existing Perspectives," Journal of the Academy of Marketing Science, 37 (4), 422-39.

-Podsakoff, Philip M., Scott B. MacKenzie, and Nathan P. Podsakoff (2003), "Common Method Biases in Behavioral Research: A Critical Review of the Literature and Recommended Remedies," Journal of Applied Psychology, 88 (5), 879-903.

- Price, Linda L., Eric J. Arnould, and Patrick Tierney (1995), "Going to Extremes: Managing Service Encounters and 
Assessing Provider Performance," Journal of Marketing, 59 (April), 83-97.

Raisch, Sebastian and Julian Birkinshaw (2008), "Organizational Ambidexterity: Antecedents, Outcomes, and Moderators," Journal of Management, 34 (3), 375-409.

, Gilbert Probst, and Michael L. Tushman (2009), "Organizational Ambidexterity: Balancing Exploitation and Exploration for Sustained Performance," Organization Science, 20 (4), 685-95.

Rust, Roland T., Christine Moorman, and Peter R. Dickson (2002), "Getting Return on Quality: Revenue Expansion, Cost Reduction, or Both?" Journal of Marketing, 66 (October), 7-24.

-Satorra, Albert and Peter M. Bentler (2001), "A Scaled Difference Chi-Square Test Statistic for Moment Structure Analysis," Psychometrika, 66 (4), 507-514.

-Saxe, Robert and Barton A. Weitz (1982), "The SOCO Scale: A Measure of the Customer Orientation of Salespeople," Journal of Marketing Research, 19 (August), 343-51.

-Singh, Jagdip (2000), "Performance Productivity and Quality of Frontline Employees in Service Organizations," Journal of Marketing, 64 (April), 15-34.
-Smith, Amy K., Ruth N. Bolton, and Janet Wagner (1999), "A Model of Customer Satisfaction with Service Encounters Involving Failure and Recovery," Journal of Marketing Research, 36 (August), 356-72.

-Van Knippenberg, Daan (2000), "Work Motivation and Performance: A Social Identity Perspective," Applied Psychology: An International Review, 49 (3), 357-71.

Wegner, Daniel M. and John A. Bargh (1998), "Control and Automaticity in Social Life," in The Handbook of Social Psychology, D.T. Gilbert, S.T. Fiske, and L. Gardner, eds. New York: McGraw-Hill, 446-96.

-Weitz, Barton A. (1978), "The Relationship Between Salesperson Performance and Understanding of Customer Decision Making," Journal of Marketing Research, 15 (November), 501-516.

(1981), "Effectiveness in Sales Interactions: A Contingency Framework," Journal of Marketing, 45 (Winter), 85-103.

, Harish Sujan, and Mita Sujan (1986), "Knowledge, Motivation, and Adaptive Behavior: A Framework for Improving Selling Effectiveness," Journal of Marketing, 50 (October), 85-103. 